\title{
ERRATUM
}

\section{Acetobacter diazotrophicus sp. nov., a Nitrogen-Fixing Acetic Acid Bacterium Associated with Sugarcane}

M. GILLIS, K. KERSTERS, B. HOSTE, D. JANSSENS, R. M. KROPPENSTEDT, M. P. STEPHAN, K. R. S. TEIXEIRA, J. DÖBEREINER, AND J. DE LEY

Laboratorium voor Microbiologie en microbiële Genetica, Rijksuniversiteit, B-9000 Ghent, Belgium; Deutsche Sammlung von Mikroorganismen und Zellkulturen, D-3300 Braunschweig, Federal Republic of Germany; and EMBRAPA,

Programa Nacional de Pesquisa em Biologia do Solo, Seropédica, 23851 Rio de Janeiro, Brazil

Volume 39, no. 3, p. 361 through 364: Strain "PA 5"' should read "PAl 5"' throughout. 